Article

\title{
Unveiling the Mode of Action of Two Antibacterial Tanshinone Derivatives
}

\author{
Dongdong Wang, Wuxia Zhang, Tingting Wang, Na Li, Haibo Mu, Jiwen Zhang \\ and Jinyou Duan *
}

College of Science, Northwest A\&F University, Yangling 712100, Shaanxi, China;

E-Mails: wangdd@nwsuaf.edu.cn (D.W.); wuxia@nwsuaf.edu.cn (W.Z.);

2013051706@nwsuaf.edu.cn (T.W.); 2009010186@nwsuaf.edu.cn (N.L.);

sdnw2528@sina.com (H.M.);nwzjw@163.com (J.Z.)

* Author to whom correspondence should be addressed; E-Mail: jduan@nwsuaf.edu.cn;

Tel./Fax: +86-29-8709-2226.

Academic Editor: Iolanda Francolini

Received: 18 June 2015 / Accepted: 24 July 2015 / Published: 31 July 2015

\begin{abstract}
In this study, 2-( $N$-pyrrolidine-alkyl) tanshinones bearing pyrrolidine groups were synthesized and the antibacterial mechanism was explored. These derivatives selectively elicited antibacterial activity against Gram-positive bacteria. Moreover, their antibacterial activities were time-, concentration-dependent and persistent. It appeared that Fenton-mediated hydroxyl radicals were involved, and the disruption of cell membranes was observed. This study indicates that 2-( $N$-pyrrolidine-alkyl) tanshinones might be potential candidates as antibacterial agents.
\end{abstract}

Keywords: tanshinone; pyrrolidine; antibacterial; reactive oxygen species (ROS); membrane

\section{Introduction}

Antibiotic resistance has been a great concern due to the extensive clinical use of classical antibiotics. Thus, the development of new classes of antibiotics has become extremely important. Among all the possible candidates, natural products have attracted increasing research and clinical interest [1,2]. 
Tanshinones are a class of abietane diterpene compounds isolated from Salvia miltiorrhiza (Danshen), a well-known herb in Traditional Chinese Medicine (TCM) [3,4]. Since they were first identified in the 1930s [5], more than 40 lipophilic and structurally related compounds have been isolated from Danshen. Among the compounds, tanshinone IIA (Tan IIA), tanshinone I (Tan I), dihydrotanshinone and cryptotanshinone (Figure 1) are the four most extensively studied [6]. Cryptanshinone and dihydrotanshinone exhibit antibacterial activity against a broad range of Gram-positive bacteria, however, Tan IIA and Tan I are not toxic to bacteria [7,8]. Tanshinones are generally composed of four rings, including naphthalene or tetrahydronaphthalene ring $\mathbf{A}$ and $\mathbf{B}$, an ortho-quinone ring $\mathbf{C}$, and furan or dihydrofuran ring $\mathbf{D}[9,10]$. The unique structures with potential therapeutic functions have sparked much interest among researchers, and a series of derivatives with modification in ring $\mathbf{D}$ have been synthesized [11]. Sodium tanshinone IIA sulfonate is a water soluble derivative of tanshinone IIA and has been used in China as a treatment for angina pectoris and myocardial infarction. Moreover, saturated fatty acid, unsaturated fatty acid, or $N$-containing substituent at $\alpha$-position of furan ring $\mathbf{D}$ were synthesized $[9,12,13]$. Additionally, it was reported that alkylated pyrrolidine-modified quinones increase serum half-life and potency against Gram-positive bacteria $[14,15]$. Thus, 2-( $N$-pyrrolidine-alkyl) tanshinones bearing pyrrolidine groups were synthesized and the antibacterial mechanism was explored.

According to the Mannich reaction, the active hydrogen atom at $\alpha$-position of furan ring $\mathbf{D}$, an aldehyde component (formaldehyde solution), and an amine reagent (pyrrolidine) led to the Mannich base of 2-( $N$-pyrrolidine-alkyl) tanshinone IIA (compound A) and 2-( $N$-pyrrolidine-alkyl) tanshinone I (compound B) [16]. Using the tanshinone derivatives, we examined the potential antibacterial activity and investigate the mechanism of the antibacterial activity on Staphylococcus aureus [17-19].

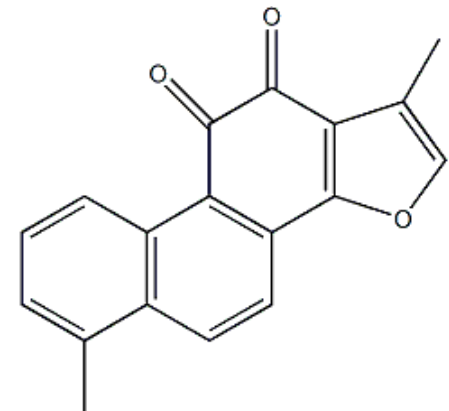

Tanshinone I

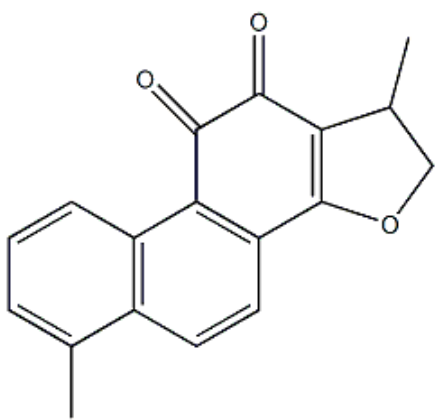

Dihydrotanshinone

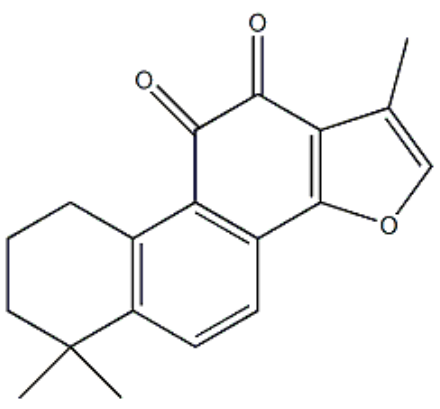

Tanshinone II A<smiles>CC1COC2=C1C(=O)C(=O)c1c2ccc2c1CCCC2(C)C</smiles>

Cryptotanshinone

Figure 1. Chemical structures of tanshinone I, tanshinone IIA, dihydrotanshinone and cryptotanshinone. 


\section{Results and Discussion}

\subsection{Preparation of Compound $\boldsymbol{A}$ and Compound $\boldsymbol{B}$}

The synthesis pathway leading to the title compounds is depicted in Scheme 1. Compound $\mathbf{A}$ or $\mathbf{B}$ was achieved by Mannich reaction according to the published method [11,20], the structures were elucidated by ${ }^{1} \mathrm{H}$ NMR, ${ }^{13} \mathrm{C}$ NMR and Mass Spectrometry (MS), which are in agreement with a previous report [11]. For the two compounds, the signal of the active hydrogen atom of the furan ring was at $7.25 \mathrm{ppm}$ (Figures $\mathrm{S} 5$ and $\mathrm{S} 6$ ), the disappearance of signals at $7.25 \mathrm{ppm}$ and the appearance of 3.70-3.77 ppm $\left(\mathrm{CH}_{2} \mathrm{~N}\right.$ ), 1.74-1.94 ppm (pyrrolidine $\mathrm{C}_{1}, \mathrm{C}_{4} \mathrm{H}$ ) and 2.65-2.74 ppm (pyrrolidine $\mathrm{C}_{2}$, $\mathrm{C}_{5} \mathrm{H}$ ) (Figures $\mathrm{S} 1$ and $\mathrm{S} 3$ ) in the compounds confirmed the synthesis of compound $\mathbf{A}$ or $\mathbf{B}$ successful.

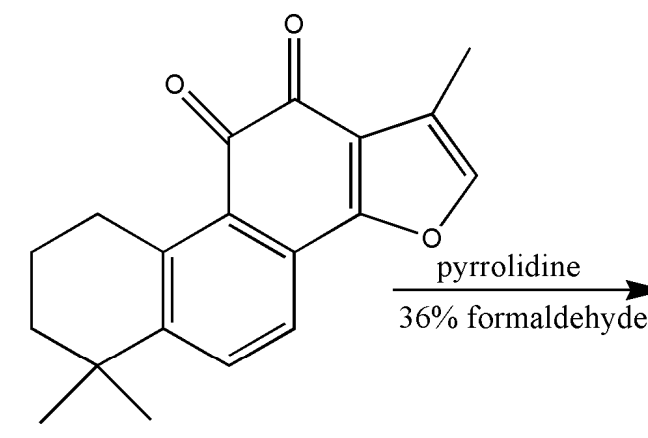

Tan II A

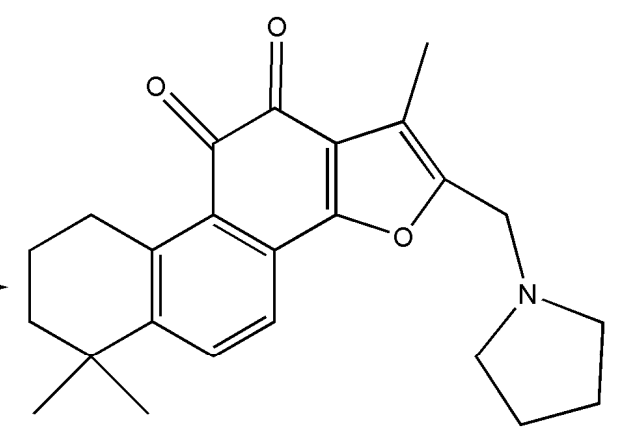

Compound A

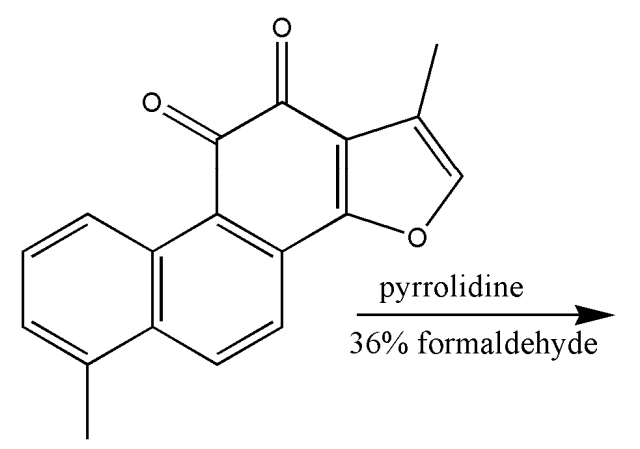

Tan I<smiles>Cc1c(CN2CCCC2)oc2c1C(=O)C(=O)c1c-2ccc2c(C)cccc12</smiles>

Compound $\mathbf{B}$

Scheme 1. Synthesis of compound $\mathbf{A}$ and compound $\mathbf{B}$.

\subsection{Determination of Minimal Inhibitory Concentration (MIC) and Minimal Bactericidal}

Concentration $(M B C)$

With compound A, compound $\mathbf{B}$, Tan IIA and Tan I in hand, the antibacterial activity was evaluated using the broth microdilution susceptibility method against the reference strains of Gram-positive and Gram-negative bacterial species [21].

MIC is reported as the lowest concentration $(\mu \mathrm{g} / \mathrm{mL})$ of drug that visually inhibits growth of the organism [22]. MBC is determined subsequent to MIC testing by sub-culturing diluted aliquots from wells that fail to exhibit macroscopic growth, and is defined as the lowest concentration $(\mu \mathrm{g} / \mathrm{mL})$ of compound exhibiting $99.9 \%$ kill over the same time period used to determine MIC. MBC values 16 times higher than MIC typically indicate antibacterial tolerance [23]. The MBC was determined 
based on Colony Forming Units (CFU) enumerated from Tryptic Soy Broth (TSB) agar plates. If the compound lacks bactericidal activity, the CFUs are too numerous to count and thus reported not determined ( $\mathrm{nd}$ ).

As shown in Table 1, Tan IIA and Tan I did not exhibit antibacterial activity for both Gram-positive and Gram-negative bacteria (MIC $>128 \mu \mathrm{g} / \mathrm{mL}$ ). Compound A and B selectively inhibited Gram-positive bacteria, with the MIC from 8 to $16 \mu \mathrm{g} / \mathrm{mL}$, however, the compounds were not toxic to Gram-negative bacteria (MIC $>64 \mu \mathrm{g} / \mathrm{mL}$ ). The $\mathrm{MBC}$ of compound A and B for the Gram-positive bacteria ranged from $2 \times$ to $8 \times$ MIC (compound A for Listeria monocytogenes), which indicated that the bacteria were susceptible to the compounds. Taking account of the value of MBC/MIC, Staphylococcus aureus (S. aureus) was used for the following experiments.

Table 1. Antibacterial activity of Tan IIA, Tan I, compound $\mathbf{A}$ and compound $\mathbf{B}$ against Gram-positive and Gram-negative bacteria.

\begin{tabular}{cccccc}
\hline \multicolumn{7}{c}{ MIC/MBC $(\boldsymbol{\mu g} / \mathbf{m L})$} \\
\hline Gram Category & Microorganisms & Tan IIA & Compound A & Tan I & Compound B \\
\hline \multirow{2}{*}{$\mathrm{G}^{-}$} & E. coli & $>128 / \mathrm{n} \mathrm{d}$ & $>64 / \mathrm{n} \mathrm{d}$ & $>128 / \mathrm{n} \mathrm{d}$ & $>64 / \mathrm{n} \mathrm{d}$ \\
& P. aerurginosa & $>128 / \mathrm{n} \mathrm{d}$ & $>64 / \mathrm{n} \mathrm{d}$ & $>128 / \mathrm{n} \mathrm{d}$ & $>64 / \mathrm{n} \mathrm{d}$ \\
& S. typhimurium & $>128 / \mathrm{n} \mathrm{d}$ & $>64 / \mathrm{n} \mathrm{d}$ & $>128 / \mathrm{n} \mathrm{d}$ & $>64 / \mathrm{n} \mathrm{d}$ \\
\hline \multirow{2}{*}{$\mathrm{G}^{+}$} & S. aureus & $>128 / \mathrm{n} \mathrm{d}$ & $16 / 64$ & $>128 / \mathrm{n} \mathrm{d}$ & $8 / 16$ \\
& L. monocytogenes & $>128 / \mathrm{n} \mathrm{d}$ & $16 / 128$ & $>128 / \mathrm{n} \mathrm{d}$ & $8 / 16$ \\
\hline
\end{tabular}

$\mathrm{G}^{-}$: Gram-negative bacteria; $\mathrm{G}^{+}$: Gram-positive bacteria; MIC: minimum inhibitory concentration; MBC: minimum bactericidal concentration; $\mathrm{n}$ d: not determined.

\subsection{Time-Kill Assay}

To obtain some insight and information on the mode of action of the antibacterial compounds, compound A and B were selected to conduct complementary lethality assays. The study is useful for the determination of whether the agents produce concentration-dependent or time-dependent killing and whether the agents have antibacterial or bactericidal profile $[24,25]$.

The time-kill curves of compound $\mathbf{A}$ and $\mathbf{B}$ against $S$. aureus are represented in Figure 2. For both compound $\mathbf{A}$ and $\mathbf{B}$, the killing kinetics were time-dependent and concentration-dependent. Compound A was bactericidal at $2 \times$ and $4 \times$ MIC levels, with a time to bactericidal killing of about $4 \mathrm{~h}$ (Figure 2a), and the bactericidal killing also observed in $12 \mathrm{~h}$ at the concentration of $1 \times$ MIC. Similar results were observed for compound B at $2 \times$ and $4 \times$ MIC levels, with bactericidal killing observed at five hour and $12 \mathrm{~h}$ points. Additionally, cells treated with compound $\mathbf{B}$ at the concentration of $1 \times$ MIC did not exhibit killing within $12 \mathrm{~h}$ (Figure 2b) [26]. The results indicate that compound A and $\mathbf{B}$ were bactericidal agents and they produced concentration-dependent and time-dependent killing. 

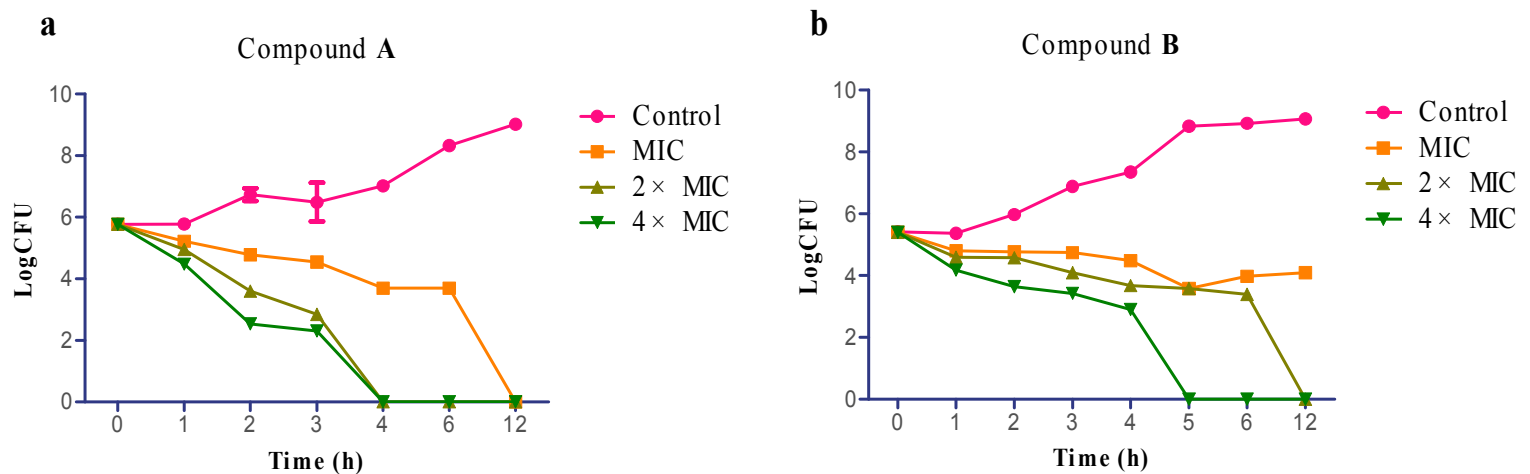

Figure 2. Time-kill assays. Time-kill curves performed in Tryptic Soy Broth (TSB) at 1×, $2 \times, 4 \times$ MIC levels of compound A (a), compound B (b) against the Staphylococcus aureus. All experiments were performed in triplicate.

\subsection{Evaluation of Postcontact Effect (PCE)}

To assess whether the antibacterial effects of compound $\mathbf{A}$ and $\mathbf{B}$ are persistent, we investigated Postcontact Effect (PCE) on S. aureus. PCE, derived from the Postantibiotic Effect (PAE), is used to measure the suppression of microbial growth that persists after antibacterial exposure [27,28]. Viable counts decreased after exposure to the two compounds at the concentration of $1 \times$ MIC and $2 \times$ MIC and did not increase for at least $3 \mathrm{~h}$ thereafter. PCE values were both about $2 \mathrm{~h}$ at $1 \times$ MIC for compound $\mathbf{A}$ and $\mathbf{B}$, about $3 \mathrm{~h}$ for compound $\mathbf{A}$ and $4 \mathrm{~h}$ for compound $\mathbf{B}$ at $2 \times$ MIC (Figure 3), showing a sensitive slowing in growth. Bacterial growth increased after $5 \mathrm{~h}$, but the $\mathrm{CFU} / \mathrm{mL}$ value of pretreated cultures at less than $24 \mathrm{~h}$ were lower than the untreated cultures. These data confirmed the bactericidal activity of the agents and the PCE experiments showed that exposure to compound $\mathbf{A}$ and $\mathbf{B}$ had a mild persistent antibacterial effect at the time points investigated. This may reflect that the anti-staphylococcal effects with these compounds is mediated by non-specific interactions with membrane bilayers. This also showed a mild effect on the growth rate of surviving bacteria, which had not recovered within $24 \mathrm{~h}$ from the end of exposure [29].

a

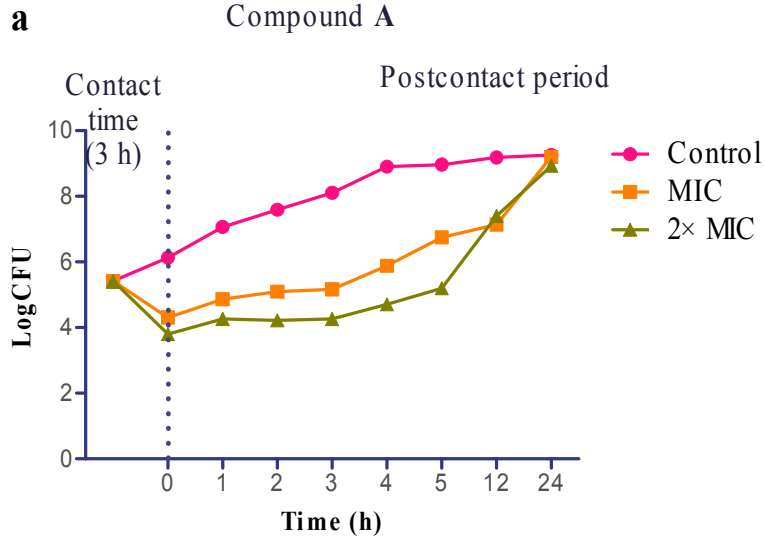

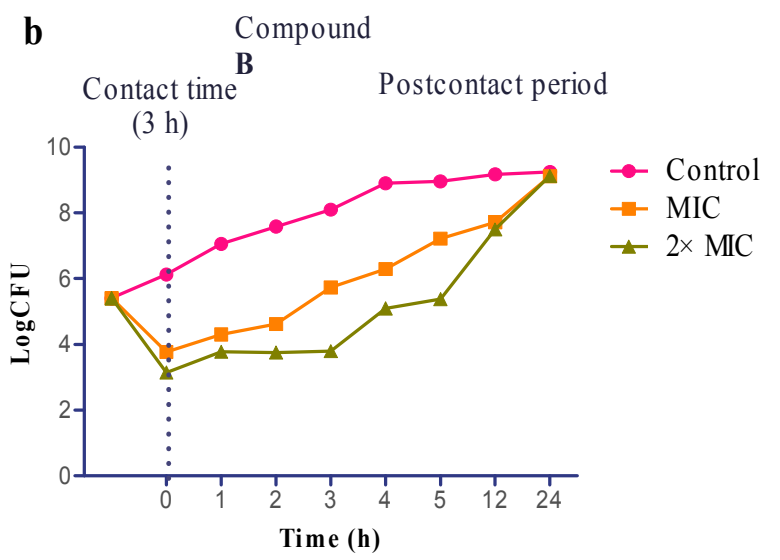

Figure 3. Evaluation of postcontact effect (PCE). The PCE of compound A (a), compound B (b) on S. aureus growth. All experiments were performed in triplicate. 


\subsection{Involvement of Hydroxyl Radical in Staphylococcus aureus Inactivation}

To demonstrate that hydroxyl radical formation is an important component of compound A-, B-mediated killing, S. aureus exposed to compound A or $\mathbf{B}$ were treated with or without the iron chelator, 2,2'-dipyridyl and the radical quencher, thiourea [30,31]. Each experiment was determined in triplicate, and the average of CFU/mL is presented in Figure 4.

For the two bactericidal agent treatments, we observed a significant increase about $3 \log \mathrm{CFU} / \mathrm{mL}$ (Figure 4a,b) in bacterial survival following the addition of 2,2'-dipyridyl, confirming that the Fenton-mediated hydroxyl radicals are involved in compound $\mathbf{A}-$ and $\mathbf{B}$-induced cell death. Reduced hydroxyl radical formation significantly increased the bacterial survival. To directly block the harmful effects of hydroxyl radicals generated via the Fenton reaction, the radical quencher thiourea was added to the treated cultures. The cultures exposed to thiourea with compound A or $\mathbf{B}$ showed the delay in cell death at $1 \mathrm{~h}$ and about $3 \log \mathrm{CFU} / \mathrm{mL}$ increase in survival at $3 \mathrm{~h}$ relative to the bactericidal agent treatments alone (Figure 4c,d). The results with 2,2'-dipyridyl and thiourea indicated that hydroxyl radical formation and the Fenton reaction played a critical role in effective killing by compound $\mathbf{A}$ and $\mathbf{B}$. However, thiourea was less efficient at mitigating bacterial cell death after the compounds treatment, which was reflected by the capacity of thiourea to reduce, but not eliminate, the compound A-, B-mediate hydroxyl radical formation, and this requires further investigation [18,32].

a
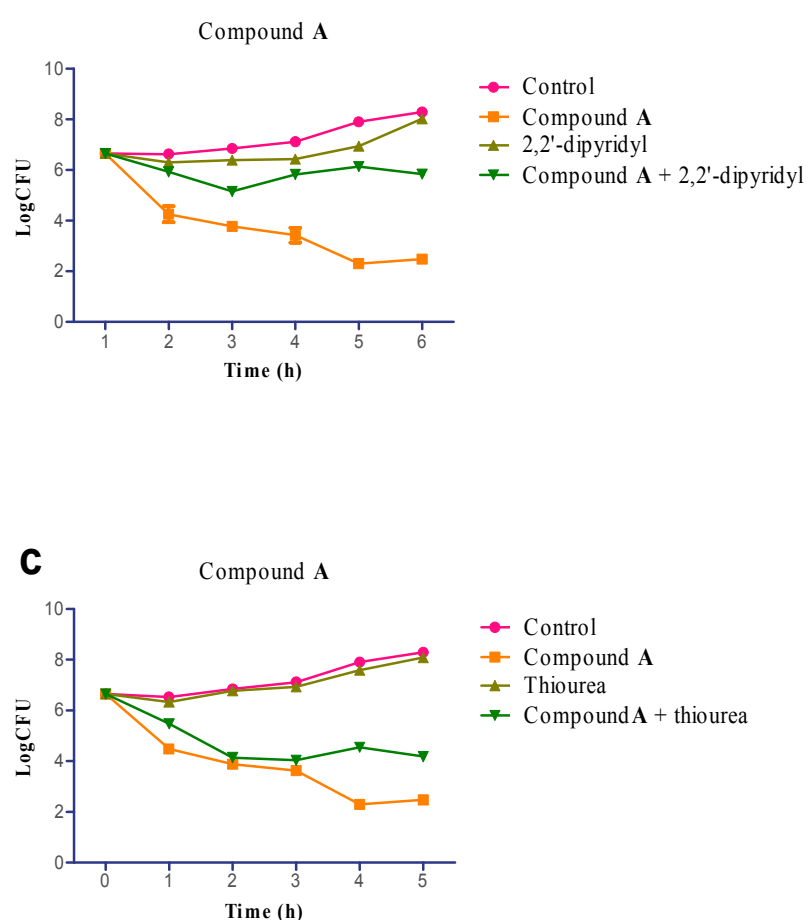

b
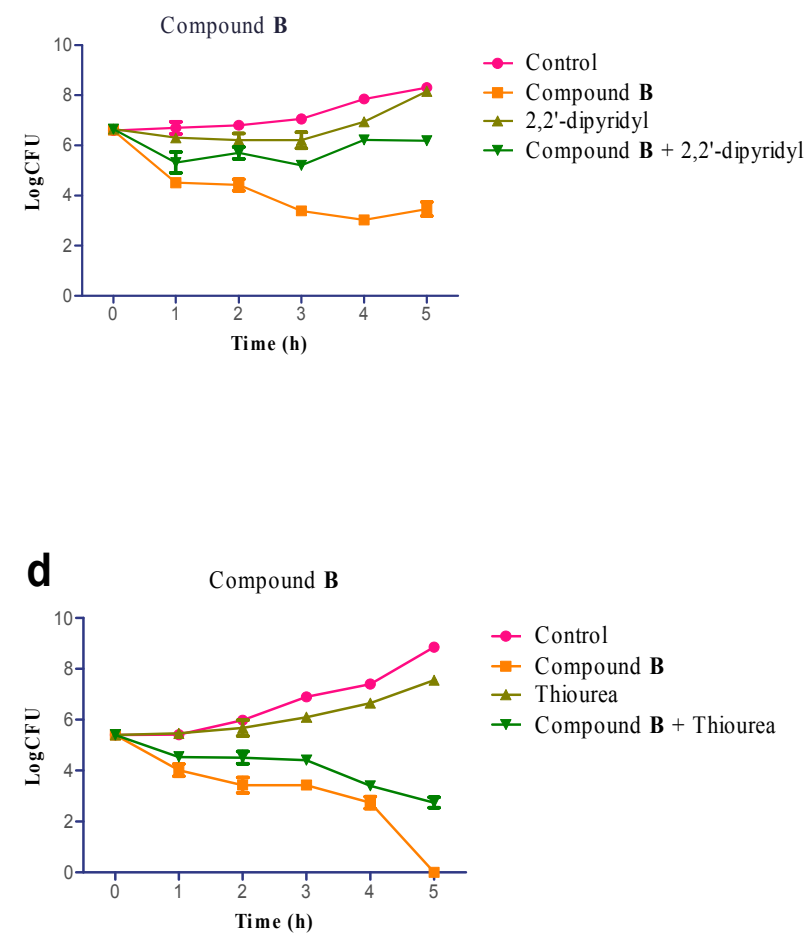

Figure 4. Involvement of hydroxyl radicals in $S$. aureus inactivation. The survival counts of cells treated with compound $\mathbf{A}(32 \mu \mathrm{g} / \mathrm{mL})$ or compound via $\mathbf{B}(32 \mu \mathrm{g} / \mathrm{mL})$ following the addition of $500 \mu \mathrm{M}$ 2,2'-dipyridyl $(\mathbf{a}, \mathbf{b})$ or $150 \mathrm{mM}$ thiourea $(\mathbf{c}, \mathbf{d})$. All experiments were performed in triplicate. 


\subsection{Scanning Electron Microscope (SEM)}

$S$. aureus was treated with the compounds at $1 \times$ and $2 \times$ MIC for $3 \mathrm{~h}$, and the morphological changes were observed by Scanning Electron Microscope (SEM). Figure 5 showed that the untreated bacterial cells exhibited bright and smooth surface with no visible damage, whereas morphological alternations were spotted on the surface of the treated cells, especially at the concentration of $2 \times$ MIC of compound $\mathbf{A}$ and $\mathbf{B}$. The treated cells became irregular, pitted, and shriveled (marked by the red arrows). The morphological alternations on the surface might result in the leakage of contents of the cells.
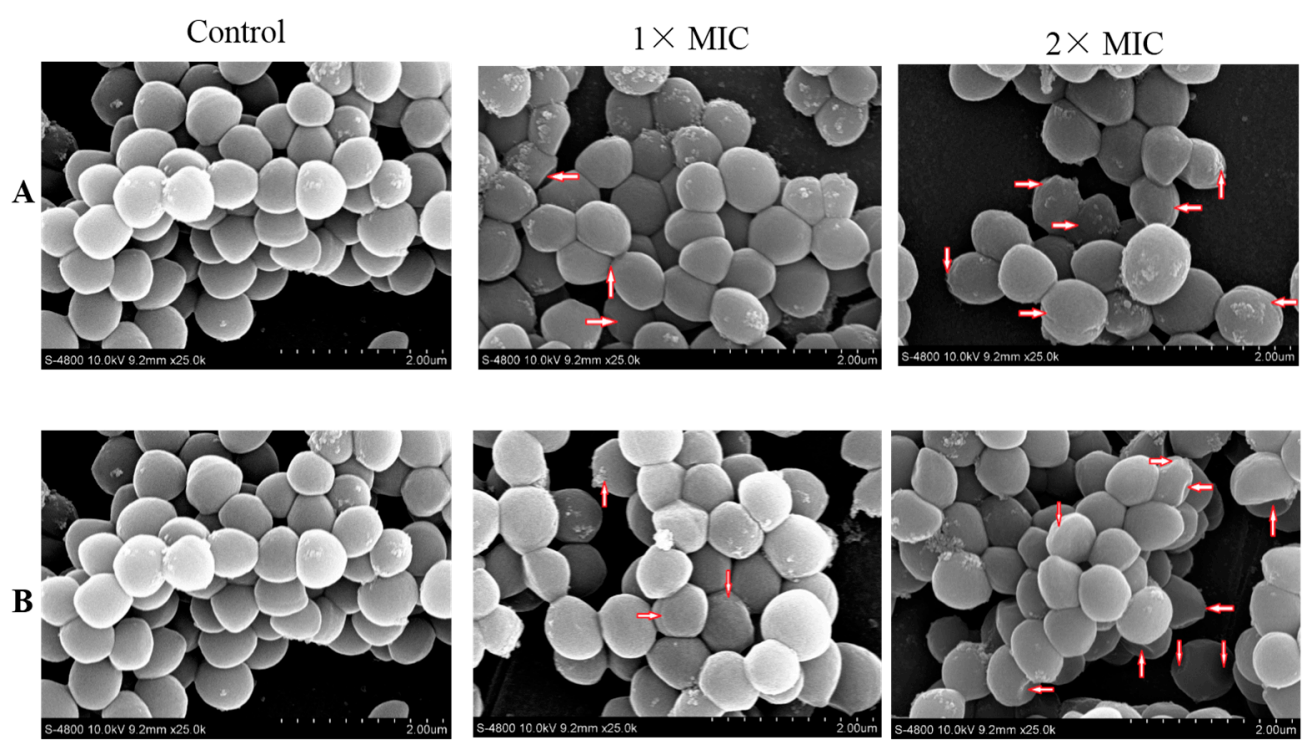

Figure 5. The Scanning Electron Microscope (SEM) photography of S. aureus. Untreated bacteria cultured for $3 \mathrm{~h}(\mathbf{A}, \mathbf{B})$; bacteria treated with compound $\mathbf{A}$ at $1 \times, 2 \times \mathrm{MIC}(\mathrm{A} 1, \mathrm{~A} 2)$; bacteria treated with compound $\mathbf{B}$ at $1 \times, 2 \times \operatorname{MIC}(\mathrm{B} 1, \mathrm{~B} 2)$. The experiment were performed two times with similar results each time. The red arrows represent the observed morphological changes.

\subsection{Cell Constituents' Release}

The bacterial membrane serves as a structural component which may be compromised during biocidal challenges, such as exposure to some antibacterial agents. Leakage of cytoplasmic contents is a classic indication of damage to the bacterial cytoplasmic membrane. Therefore, release of intracellular components is a good indicator of membrane integrity. Small ions, such as potassium and phosphate, tend to leach out first, followed by large molecules, such as DNA, RNA and other materials. These nucleotides have strong UV absorptions at $260 \mathrm{~nm}$ and are thus described as $260 \mathrm{~nm}$ absorbing materials $[33,34]$.

The UV absorptions of $S$. aureus culture supernatants are shown in Figure 6, the release of $260 \mathrm{~nm}$ absorbing materials from the $S$. aureus quickly increased when treated with compound $\mathbf{A}$ and $\mathbf{B}$ at $1 \times$ MIC and $2 \times$ MIC for $4 \mathrm{~h}$, significantly higher than that for control values. Continuing incubation for another $4 \mathrm{~h}$, the absorbance at $260 \mathrm{~nm}$ increased to the higher level. The results indicate that the cell membrane integrity was damaged when the cells were exposed to $1 \times$ MIC and $2 \times$ MIC of compound $\mathbf{A}$ and $\mathbf{B}$. The alterations correlate with the ability of compound $\mathbf{A}$ and $\mathbf{B}$ to interact 
with hydrophobic structures, such as bacterial membranes [35]. The lipophilic antibacterial agents seem related to direct interaction with the hydrophobic regions of membrane proteins or protein complexes [36,37], resulting in alternation of membrane permeability and leakage of intracellular materials [38].

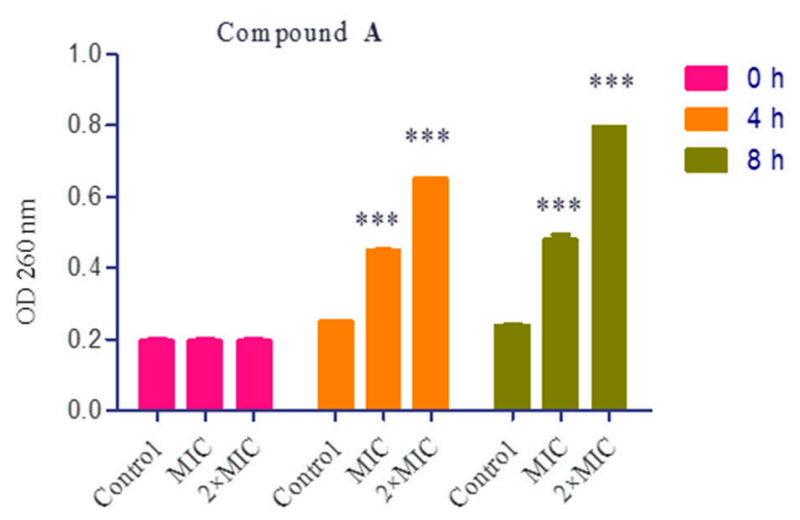

(a)

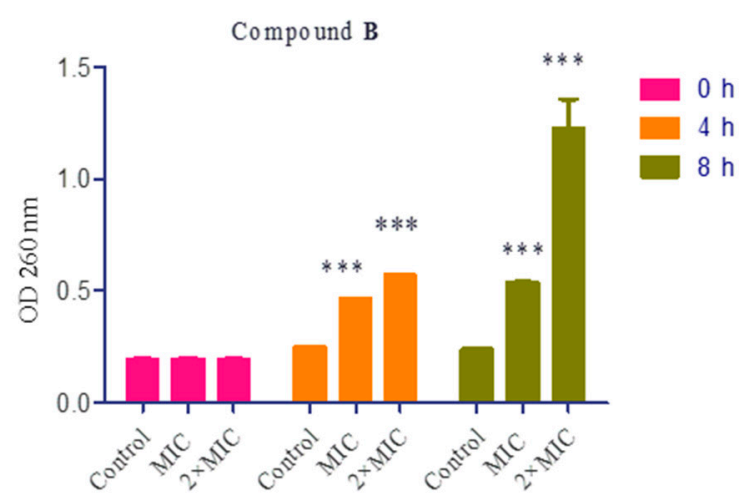

(b)

Figure 6. Loss of $260 \mathrm{~nm}$ absorbing material. S. aureus cells were treated with compound A (a) and compound $\mathbf{B}(\mathbf{b})$ at $1 \times, 2 \times$ MIC, respectively. All experiments were performed in triplicate. The asterisks denote statistical significance $(p<0.05)$ between the control and the treatments ( $1 \times$ MIC and $2 \times$ MIC) of compound A and B obtained from Tukey's test. OD: optical density.

\section{Materials and Methods}

\subsection{Chemistry}

All reagents were purchased from Aladdin Industrial Corporation and used without further purification, unless otherwise stated. Some solvents were dried prior to use according to standard methods. The reactions were monitored by Thin Layer Chromatography (TLC) on silica gel GF254. Detection was made by both UV light and charring with sulfuric acid/ethanol solution. Column chromatography was performed on silica gel 200-300 mesh. The ${ }^{1} \mathrm{H}$ NMR, ${ }^{13} \mathrm{C}$ NMR spectra were recorded on a Bruker AV500 $\mathrm{MHz}$ (Bruker, Switzerland) instrument using $\mathrm{CDCl}_{3}$ as solvents.

\subsubsection{Preparation of Compound A}

A mixture of tanshinone IIA $(29.4 \mathrm{mg}, 0.1 \mathrm{mmol})$, pyrrolidine (15.6 $\mathrm{mg}, 0.2 \mathrm{mmol}), 36 \%$ formaldehyde solution $(18 \mathrm{mg})$ in acetic acid $(20 \mathrm{~mL})$ was stirred at $20^{\circ} \mathrm{C}$ for $1 \mathrm{~h}$, then stirred under reflux at $90{ }^{\circ} \mathrm{C}$ for $9 \mathrm{~h}$. Next, the solution was cooled and washed three times with sodium carbonate solution, and extracted with dichloromethane. The organic phase was evaporated and the residue was purified by column chromatography on silica gel (Eluent:ethyl acetate/petroleum ether, 7:10) to produce compound $\mathbf{A}\left(23.9 \mathrm{mg}, 63.5 \%\right.$ yield) as orange solid. ${ }^{1} \mathrm{H}$ NMR (500 $\left.\mathrm{MHz}, \mathrm{CDCl}_{3}\right)$ $\delta 7.65(\mathrm{~s}, 2 \mathrm{H}), 7.31(\mathrm{~s}, 1 \mathrm{H}), 3.71(\mathrm{~s}, 2 \mathrm{H}), 3.22(\mathrm{t}, J=6.4 \mathrm{~Hz}, 2 \mathrm{H}), 2.65(\mathrm{~s}, 4 \mathrm{H}), 2.30(\mathrm{~s}, 3 \mathrm{H})$, 1.94-1.74 (m, 4H), 1.73-1.65 (m, 4H), $1.35(\mathrm{~s}, 6 \mathrm{H})$ (Figure $\mathrm{S} 1) ;{ }^{13} \mathrm{C}$ NMR $\left(126 \mathrm{MHz}, \mathrm{CDCl}_{3}\right)$ $\delta 183.79,175.89,160.63,150.00,144.41,133.36,127.43,126.51,120.59,120.41,99.99,53.98,49.25$, 
37.90, 34.67, 31.87, 29.92, 23.51, 19.16, 9.01 (Figure S2); MS $\left(\mathrm{m} / \mathrm{z}\right.$ ): calcd for $\mathrm{C}_{24} \mathrm{H}_{27} \mathrm{NO}_{3}$ : 377; found: $378.04[\mathrm{M}+\mathrm{H}]^{+}$(Figure S7).

\subsubsection{Preparation of Compound $\mathbf{B}$}

A mixture of tanshinone I (27.6 mg, $0.1 \mathrm{mmol})$, pyrrolidine (15.6 mg, $0.2 \mathrm{mmol}), 36 \%$ formaldehyde solution $(18 \mathrm{mg})$ in acetic acid $(20 \mathrm{~mL})$ was stirred at $20^{\circ} \mathrm{C}$ for $1 \mathrm{~h}$, stirred under reflux at $90{ }^{\circ} \mathrm{C}$ for $9 \mathrm{~h}$. Next, the solution was cooled and washed three times with sodium carbonate solution, extracted with dichloromethane. The organic phase was evaporated and the residue was purified by column chromatography on silica gel (Eluent:ethyl acetate/petroleum ether, 3:5) to produce compound $\mathbf{B}\left(19.4 \mathrm{mg}, 53.9 \%\right.$ yield) as purple solid. ${ }^{1} \mathrm{H}$ NMR $\left(500 \mathrm{MHz}, \mathrm{CDCl}_{3}\right)$ $\delta 9.30(\mathrm{~d}, J=8.8 \mathrm{~Hz}, 1 \mathrm{H}), 8.34(\mathrm{~d}, J=8.7 \mathrm{~Hz}, 1 \mathrm{H}), 7.93(\mathrm{~d}, J=8.7 \mathrm{~Hz}, 1 \mathrm{H}), 7.60(\mathrm{~d}, J=8.8,7.0 \mathrm{~Hz}, 1 \mathrm{H})$, $7.40(\mathrm{~d}, J=6.9 \mathrm{~Hz}, 1 \mathrm{H}), 3.84-3.72(\mathrm{~m}, 2 \mathrm{H}), 2.75$ (d, $J=9.1 \mathrm{~Hz}, 4 \mathrm{H}), 2.42-2.23(\mathrm{~m}, 3 \mathrm{H}), 1.86$ (d, $J=59.3 \mathrm{~Hz}, 4 \mathrm{H}), 1.36-1.15(\mathrm{~m}, 3 \mathrm{H})$ (Figure S3); ${ }^{13} \mathrm{C} \mathrm{NMR}\left(126 \mathrm{MHz}, \mathrm{CDCl}_{3}\right) \delta 183.53,175.75,160.25$, 135.24, 133.70, 132.85, 130.67, 129.57, 128.37, 124.80, 123.23, 120.97, 119.11, 99.99, 53.84, 49.01, 23.49, 19.88, 9.02 (Figure S4); $\mathrm{MS}\left(\mathrm{m} / \mathrm{z}\right.$ ): calcd for $\mathrm{C}_{23} \mathrm{H}_{21} \mathrm{NO}_{3}: 359$; found: $359.98[\mathrm{M}+\mathrm{H}]^{+}$(Figure S8).

\subsection{Biology}

\subsubsection{Bacterial Strains and Growth Conditions}

Gram-positive strains: Staphyloccocus aureus (ATCC 29213, Guangzhou, China), Listeria monocytogenes (CMCC 54004, Guangzhou, China), Gram-negative strains: Pseudomonas aeruginosa (PAO1), Escherichia coli (ATCC 35150) and Salmonella typhimurium (SL1344) were purchased from the National Center for Medical Culture Collection (CMCC). The strains were cultured in Tryptic Soy Broth (TSB) at $37^{\circ} \mathrm{C}$. Active cultures were prepared by transferring a loop of cells from the TSB agar slant to a flask $(50 \mathrm{~mL})$ containing $30 \mathrm{~mL}$ TSB. They were then incubated at $37{ }^{\circ} \mathrm{C}$ to the logarithmic phase of growth. Culture purity was examined by streaking each culture on plates of TSB Agar. The turbidity of the cell suspensions was measured at $600 \mathrm{~nm}$ and adjust to the required concentration using the McFarland standard [39]. All bacterial strains were maintained as glycerol stocks at $-80{ }^{\circ} \mathrm{C}$.

\subsubsection{Minimal Inhibitory Concentration (MIC) and Minimal Bactericidal Concentration (MBC)}

Two-fold dilutions of compound $\mathbf{A}$ and $\mathbf{B}$ were prepared in a sterile flat-bottomed 96-well polystyrene microplates in TSB, then bacteria with the final concentration of $1.2 \times 10^{6} \mathrm{CFU} / \mathrm{mL}$ in TSB per well inoculated at $37{ }^{\circ} \mathrm{C}$ for $24 \mathrm{~h}$, and bacteria incubated in TSB containing $0.64 \%(v / v)$ DMSO were used as control. MBC is determined subsequent to MIC testing by sub-culturing diluted aliquots from wells that failed to exhibit macroscopic growth. The sample aliquots were inoculated onto TSB agar plates and subsequently incubated at $37{ }^{\circ} \mathrm{C}$ for $24 \mathrm{~h}$. The bacterial colonies were enumerated while the growth was readily apparent. 


\subsubsection{Time-Kill Assay}

Cultures of $S$. aureus (about $6 \times 10^{5} \mathrm{CFU} / \mathrm{mL}$ ) at $37{ }^{\circ} \mathrm{C}$ were grown in TSB supplemented with $1 \times$, $2 \times$, and $4 \times$ the MIC of compound $\mathbf{A}(\mathrm{MIC}=16 \mu \mathrm{g} / \mathrm{mL})$ and $\mathbf{B}(\mathrm{MIC}=8 \mu \mathrm{g} / \mathrm{mL})$, with $0.32 \%$ and $0.64 \%(v / v)$ DMSO as controls. The number of CFU/mL was measured from aliquots $(0,1,2,3,4$, $6,12 \mathrm{~h}$ ) that were serially diluted in sterile saline, planted on TSB agar, incubated at $37{ }^{\circ} \mathrm{C}$, and the colonies were enumerated after $18 \mathrm{~h}$. The time-dependent killing curves were constructed by plotting mean colony counts over time.

\subsubsection{Evaluation of Postcontact Effect (PCE)}

The cultures of $S$. aureus (about $6 \times 10^{5} \mathrm{CFU} / \mathrm{mL}$ ) were grown in media supplemented with $1 \times$, $2 \times$ MIC of the compound $\mathbf{A}$ and $\mathbf{B}$ for $3 \mathrm{~h}$ at $37{ }^{\circ} \mathrm{C}, 0.32 \%$ and $0.64 \%(v / v)$ DMSO as controls. The cultures were washed three times in sterile saline by centrifugation at $3500 \mathrm{rpm}$ for $20 \mathrm{~min}$ and then transferred to fresh TSB before incubation at $37{ }^{\circ} \mathrm{C}$. The number of $\mathrm{CFU} / \mathrm{mL}$ was measured from aliquots that were serially diluted in sterile saline, and planted on the TSB agar immediately and 1, 2, 3, $4,5,12,24 \mathrm{~h}$ after incubation. PCE was determined using the equation:

$$
\mathrm{PCE}=\mathrm{t}-\mathrm{c}
$$

where $t$ was the time needed for a log increase in counts in treated cultures and $\mathrm{c}$ was the time needed for a log increase in counts in untreated cultures. All the experiments were performed in triplicate.

\subsubsection{Iron Chelator and Hydroxyl Radical Quenching Experiments}

2,2-dipyridyl, dissolved in ethanol $(0.5 \mathrm{~mol} / \mathrm{L})$, was added to the culture with or without compound $\mathbf{A}$ and $\mathbf{B}$ at a final concentration of $500 \mu \mathrm{M}$, thiourea in solid form was weighed and added to the culture with or without compound $\mathbf{A}$ and $\mathbf{B}$ to achieve a final concentration of $150 \mathrm{mM}$, the cultures with $0.32 \%$ and $0.64 \%$ DMSO as controls. All the culture of $S$. aureus was adjusted to approximately $10^{7} \mathrm{CFU} / \mathrm{mL}$ and cultured at $37^{\circ} \mathrm{C}$. The number of $\mathrm{CFU} / \mathrm{mL}$ was measured from aliquots that were serially diluted in sterile saline, planted on the TSB agar immediately and 1, 2, 3, 4, $5 \mathrm{~h}$ after incubation. The curves were constructed by plotting mean colony counts over time.

\subsubsection{Scanning Electron Microscope (SEM)}

Compound $\mathbf{A}$ and $\mathbf{B}$ were added at either the $1 \times$ MIC or $2 \times$ MIC in the culture of $S$. aureus of $1.2 \times 10^{6} \mathrm{CFU} / \mathrm{mL}, 0.64 \%(v / v)$ DMSO as control. All suspensions were incubated at $37^{\circ} \mathrm{C}$ for $3 \mathrm{~h}$, and then centrifuged at $3500 \mathrm{rpm}$ for $20 \mathrm{~min}$. All the cells were washed twice with $0.1 \mathrm{M}$ phosphate buffer saline (PBS, pH 7.4) and fixed with 2.5\% glutaraldehyde $(v / v)$ in $0.1 \mathrm{M}$ PBS at $4{ }^{\circ} \mathrm{C}$ for $24 \mathrm{~h}$. Next, the cells were dehydrated using 30\%, 50\%, 70\%, 90\%, and 100\% ethanol, and then the ethanol was replaced by tertiary butyl alcohol. The cells were dried at "critical point" in liquid $\mathrm{CO}_{2}$, and the samples were gold-covered by cathodic spraying before examination [40,41]. 


\subsubsection{Cell Constituents' Release}

The experiments were conducted followed a published method [33]. Briefly, the bacterial cells incubated in TSB were adjusted to about $10^{8} \mathrm{CFU} / \mathrm{mL}$. The bacterial suspensions was centrifuged at $5000 \mathrm{rpm}$ for $10 \mathrm{~min}$, washed twice by using the PBS (pH 7.4) and resuspended in sterile saline. Compound $\mathbf{A}$ and $\mathbf{B}$ were added to reach the final concentration at $1 \times \mathrm{MIC}$ and $2 \times \mathrm{MIC}$. About $3 \mathrm{~mL}$ media was removed from the flasks after $0,4,8 \mathrm{~h}$ of incubation at $37{ }^{\circ} \mathrm{C}$. The samples were filtered using $0.22 \mu \mathrm{m}$ syringe filters to remove the bacteria, and the optical density (OD) of the supernatant at $260 \mathrm{~nm}$ was recorded using UV visible spectrophotometer. All tests were performed in triplicate. Mean OD values of respective treatments and vehicle control were compared independently at each time point.

\section{Conclusions}

Natural products have been the single most productive source of leads for the development of drugs because of the unmatched availability of chemical diversity. In practice, semisynthesis is the method of choice for lead optimization. In the current study we have synthesized 2-( $N$-pyrrolidine-alkyl) tanshinone II A and 2-( $N$-pyrrolidine-alkyl) tanshinone I successfully. Their antibacterial properties were evaluated and the antibacterial mechanism was explored. The results revealed that the two tanshinone derivatives have promising antibacterial activity against the Gram-positive bacteria, moreover, Fenton-mediated hydroxyl radicals were involved and the disruption of the cell membrane was observed in the inactivation of Gram-positive bacteria. Moreover, the hydrophobic molecules tend to be non-specific, and the mammalian cells may also be affected by the formation of hydroxyl radicals. These results indicated that 2-( $N$-pyrrolidine-alkyl) tanshinones could serve as a starting point for further optimization and promote the development of new antibacterial agents [35,42].

\section{Supplementary Materials}

Supplementary materials can be found at http://www.mdpi.com/1422-0067/16/08/17668/s1.

\section{Acknowledgments}

This project was supported by the "Interdisciplinary Cooperation Team" Program for Science and Technology Innovation of Chinese Academy of Sciences Science, as well as in part by the National Natural Science Foundation of China (NSFC) (Grant 31270860) and Program for New Century Excellent Talents in University (NCET-13-0480).

\section{Author Contributions}

Dongdong Wang and Jinyou Duan designed research and contributed new reagents/analytic tools; Dongdong Wang performed research, Wuxia Zhang, Tingting Wang and $\mathrm{Na}$ Li performed statistical analysis; Dongdong Wang and Jinyou Duan wrote the paper; Wuxia Zhang, Haibo Mu and Jiwen Zhang reviewed the manuscript. 


\section{Conflicts of Interest}

The authors declare no conflict of interest.

\section{References}

1. Butler, M.S.; Buss, A.D. Natural products-The future scaffolds for novel antibiotics? Biochem. Pharmacol. 2006, 71, 919-929.

2. Saleem, M.; Nazir, M.; Ali, M.S.; Hussain, H.; Lee, Y.S.; Riaz, N.; Jabbar, A. Antimicrobial natural products: An update on future antibiotic drug candidates. Nat. Prod. Rep. 2010, 27, 238-254.

3. Zhang, Y.; Jiang, P.; Ye, M.; Kim, S.H.; Jiang, C.; Lu, J. Tanshinones: Sources, pharmacokinetics and anti-cancer activities. Int. J. Mol. Sci. 2012, 13, 13621-13666.

4. Lee, W.Y.; Chiu, L.C.; Yeung, J.H. Cytotoxicity of major tanshinones isolated from Danshen (Salvia miltiorrhiza) on HepG2 cells in relation to glutathione perturbation. Food Chem. Toxicol. 2008, 46, 328-338.

5. Nakao, M.; Fukushima, T. On the chemical composition of Salvia miltiorrhiza (Chinese drug Tan-shen). J. Pharm. Soc. Jpn. 1934, 54, 154-162.

6. Han, J.Y.; Fan, J.Y.; Horie, Y.; Miura, S.; Cui, D.H.; Ishii, H.; Hibi, T.; Tsuneki, H.; Kimura, I. Ameliorating effects of compounds derived from Salvia miltiorrhiza root extract on microcirculatory disturbance and target organ injury by ischemia and reperfusion. Pharmacol. Ther. 2008, 117, 280-295.

7. Wang, X.; Morris-Natschke, S.L.; Lee, K.H. New developments in the chemistry and biology of the bioactive constituents of Tanshen. Med. Res. Rev. 2007, 27, 133-148.

8. Zhao, J.; Lou, J.; Mou, Y.; Li, P.; Wu, J.; Zhou, L. Diterpenoid tanshinones and phenolic acids from cultured hairy roots of Salvia miltiorrhiza Bunge and their antimicrobial activities. Molecules 2011, 16, 2259-2267.

9. Tian, X.H.; Wu, J.H. Tanshinone derivatives: A patent review (January 2006-September 2012). Expert Opin. Ther. Pat. 2013, 23, 19-29.

10. Dong, Y.; Morris-Natschke, S.L.; Lee, K.H. Biosynthesis, total syntheses, and antitumor activity of tanshinones and their analogs as potential therapeutic agents. Nat. Prod. Rep. 2011, 28, 529-542.

11. Sun, C.J.; Bai, D.L. Synthesis of some compounds related to tanshinquinone. Yao Xue Xue Bao 1985, 20, 39-43.

12. Bi, Y.F.; Wang, Z.J.; Guan, R.F.; Ye, Y.T.; Chen, Y.Y.; Zhang, Y.B.; Liu, H.M. Design, synthesis and vasodilative activity of tanshinone II A derivatives. Bioorg. Med. Chem. Lett. 2012, 22, 5141-5143.

13. Xu, S.; Liu, P. Tanshinone II-A: New perspectives for old remedies. Expert Opin. Ther. Pat. 2013, 23, 149-153.

14. Domagala, J.M. Structure-activity and structure-side-effect relationships for the quinolone antibacterials. J. Antimicrob. Chemother. 1994, 33, 685-706.

15. Chen, Y.L.; Fang, K.C.; Sheu, J.Y.; Hsu, S.L.; Tzeng, C.C. Synthesis and antibacterial evaluation of certain quinolone derivatives. J. Med. Chem. 2001, 44, 2374-2377.

16. Roman, G. Mannich bases in medicinal chemistry and drug design. Eur. J. Med. Chem. 2015, 89, 743-816. 
17. Ait-Ouazzou, A.; Espina, L.; Gelaw, T.; Lamo-Castellví, S.; Pagán, R.; García-Gonzalo, D. New insights in mechanisms of bacterial inactivation by carvacrol. J. Appl. Microbiol. 2013, 114, 173-185.

18. Chueca, B.; Pagan, R.; Garcia-Gonzalo, D. Oxygenated monoterpenes citral and carvacrol cause oxidative damage in Escherichia coli without the involvement of tricarboxylic acid cycle and Fenton reaction. Int. J. Food Microbiol. 2014, 189, 126-131.

19. Carson, C.F.; Mee, B.J.; Riley, T.V. Mechanism of action of Melaleuca alternifolia (Tea Tree) oil on Staphylococcus aureus determined by time-kill, lysis, leakage, and salt tolerance assays and electron microscopy. Antimicrob. Agents Chemother. 2002, 46, 1914-1920.

20. Plech, T.; Wujec, M.; Siwek, A.; Kosikowska, U.; Malm, A. Synthesis and antimicrobial activity of thiosemicarbazides, s-triazoles and their Mannich bases bearing 3-chlorophenyl moiety. Eur. J. Med. Chem. 2011, 46, 241-248.

21. Wikler, M.A. Methods for Dilution Antimicrobial Susceptibility Tests for Bacteria that Grow Aerobically; Approved Standard-Eighth ed.; CLSI Document M07-A8: Wayne, PA, USA, 2003.

22. Benincasa, M.; Zahariev, S.; Pelillo, C.; Milan, A.; Gennaro, R.; Scocchi, M. PEGylation of the peptide Bac7 (1-35) reduces renal clearance while retaining antibacterial activity and bacterial cell penetration capacity. Eur. J. Med. Chem. 2015, 95, 210-219.

23. Danac, R.; Mangalagiu, II. Antimycobacterial activity of nitrogen heterocycles derivatives: Bipyridine derivatives. Part III. Eur. J. Med. Chem. 2014, 74, 664-670.

24. Castro, M.A.; Gamito, A.M.; Tangarife-Castano, V.; Zapata, B.; Miguel del Corral, J.M.; Mesa-Arango, A.C.; Betancur-Galvis, L.; San Feliciano, A. Synthesis and antifungal activity of terpenyl-1,4-naphthoquinone and 1,4-anthracenedione derivatives. Eur. J. Med. Chem 2013, 67, 19-27.

25. Pournaras, S.; Vrioni, G.; Neou, E.; Dendrinos, J.; Dimitroulia, E.; Poulou, A.; Tsakris, A. Activity of tigecycline alone and in combination with colistin and meropenem against Klebsiella pneumoniae carbapenemase (KPC)-producing enterobacteriaceae strains by time-kill assay. Int. J. Antimicrob. Agents 2011, 37, 244-247.

26. Marceau A.H.; Bernstein, D.A.; Walsh, B.W.; Shapiro, W.; Simmons, L.A; Keck, J.L. Protein interactions in genome maintenance as novel antibacterial targets. PLoS ONE 2013, 8, e58765.

27. Daglia, M.; Papetti, A.; Gietroli, P.; Aceti, C.; Dacarro, C.; Gazzani, G. Antibacterial activity of red and white wine against oral streptococci. J. Agric. Food Chem. 2007, 55, 5038-5042.

28. Craig, W.A. The postantibiotic effect. Clin. Microbiol. Newsl. 1991, 13, 121-124.

29. Giguere, S.; Lee, E.A.; Guldbech, K.M.; Berghaus, L.J. In vitro synergy, pharmacodynamics, and postantibiotic effect of 11 antimicrobial agents against Rhodococcus equi. Vet. Microbiol. 2012, 160, 207-213.

30. Kohanski, M.A.; Dwyer, D.J.; Hayete, B.; Lawrence, C.A.; Collins, J.J. A common mechanism of cellular death induced by bactericidal antibiotics. Cell 2007, 130, 797-810.

31. Jensen, P.O.; Briales, A.; Brochmann, R.P.; Wang, H.; Kragh, K.N.; Kolpen, M.; Hempel, C.; Bjarnsholt, T.; Hoiby, N.; Ciofu, O. Formation of hydroxyl radicals contributes to the bactericidal activity of ciprofloxacin against Pseudomonas aeruginosa biofilms. Pathog. Dis. 2014, 70, 440-443.

32. Chueca, B.; Pagan, R.; Garcia-Gonzalo, D. Differential mechanism of Escherichia coli Inactivation by $(+)$-limonene as a function of cell physiological state and drug's concentration. PLoS ONE 2014, 9, e94072. 
33. Ghosh, S.; Indukuri, K.; Bondalapati, S.; Saikia, A.K.; Rangan, L. Unveiling the mode of action of antibacterial labdane diterpenes from Alpinia nigra (Gaertn.) B. L. Burtt seeds. Eur. J. Med. Chem. 2013, 66, 101-105.

34. Aidah, N.; Abdullah, N.; Oskoueian, E.; Sieo, C.C.; Saad, W.Z. Membrane-active antibacterial compounds in methanolic extracts of Jatropha curcas and their mode of action against Staphylococcus aureus S1434 and Escherichia coli E216. Int. J. Agric. Biol. 2014, 16, 723-730.

35. Kaur, G.; Singh, R.P. Antibacterial and membrane damaging activity of Livistona chinensis fruit extract. Food Chem. Toxicol. 2008, 46, 2429-2934.

36. Sikkema, J.; de Bont, J.A.; Poolman, B. Mechanisms of membrane toxicity of hydrocarbons. Microbiol. Rev. 1995, 59, 201-222.

37. Somolinos, M.; Garc, D.; Condon, S.; Mackey, B.; Pagan, R. Inactivation of Escherichia coli by citral. J. Appl. Microbiol. 2010, 108, 1928-1939.

38. Trombetta, D.; Castelli, F.; Sarpietro, M.G.; Venuti, V.; Cristani, M.; Daniele, C.; Saija, A.; Mazzanti, G.; Bisignano, G. Mechanisms of antibacterial action of three monoterpenes. Antimicrob. Agents Chemother. 2005, 49, 2474-2478.

39. Janssen, A.M.; Scheffer, J.J.C.; Baerheim, S.A. Antimicrobial activity of Essential oils: A 1976-1986 literature review. Aspects of the test methods. Planta Med. 1987, 53, 395-398.

40. Bandyopadhyay, N.; Zhu, M.; Lu, L.; Mitra, D.; Das, M.; Das, P.; Samanta, A.; Naskar, J.P. Synthesis, structure, spectral characterization, electrochemistry and evaluation of antibacterial potentiality of a novel oxime-based palladium(II) compound. Eur. J. Med. Chem. 2015, 89, 59-66.

41. Sun, D.; Zhang, W.; Lv, M.; Yang, E.; Zhao, Q.; Wang, W. Antibacterial activity of ruthenium(II) polypyridyl complex manipulated by membrane permeability and cell morphology. Bioorg. Med. Chem. Lett. 2015, 25, 2068-2073.

42. Schallenberger, M.A.; Newhouse, T.; Baran, P.S.; Romesberg, F.E. The psychotrimine natural products have antibacterial activity against Gram-positive bacteria and act via membrane disruption. J. Antibiot. 2010, 63, 685-687.

(C) 2015 by the authors; licensee MDPI, Basel, Switzerland. This article is an open access article distributed under the terms and conditions of the Creative Commons Attribution license (http://creativecommons.org/licenses/by/4.0/). 